\title{
AS POLÍTICAS PÚBLICAS ANTE A DESIGUALDADE: O PROGRAMA BOLSA FAMÍLIA E SUAS (IM)PERFEIÇÕES ${ }^{1}$
}

\author{
PUBLIC POLICIES TOWARDS INEQUALITY: \\ BOLSA FAMÍLIA PROGRAM AND ITS (IM)PERFECTIONS
}

\section{Rafael Pentiado Poerschke ${ }^{2}$, Paula Simone Bolzan Jardim ${ }^{3}$ e Rita Inês Paetzhold Pauli ${ }^{4}$}

\section{RESUMO}

Os programas de Transferência Condicionada de Renda (TCR) são de fundamental importância social para auxiliar na superação de situações de fome e miséria. Como toda política de Estado, além de virtudes, os programas do tipo TCR também apresentam limitações de alcance. O presente artigo, com uma abordagem exploratória e dedutiva, procurou comparar a trajetória dos reajustes do benefício assistencial pago pelo Programa Bolsa Família (PBF) à luz da legislação vigente. Essa etapa foi combinada com a utilização de dados estatísticos gerais da região de Santa Maria para apontar que a discussão da validade dos programas de complementação de renda, como o PBF, não pode se dar de forma desconectada da realidade de seu público-alvo. A criação de um parâmetro, um índice que capture as oscilações inflacionárias pertinentes às famílias de baixa renda, é notório e não está previsto pelo PBF. Em países de dimensões continentais como o Brasil, ressaltamos que a necessidade de uma avaliação periódica do valor do benefício do PBF não seria suficiente. O referido programa também padece de um olhar regional na correção dos valores pagos como benefício, uma vez que os custos de vida e hábitos da população abrangida por esse tipo de programa é muito diversa regional e culturalmente. Na ponta do lápis, havendo uma diferença, e por menor que seja esse desvio, somente uma maior aderência à realidade regional conseguirá ampliar as condições para uma vida digna.

Palavras-Chave: Transferência de Renda Condicionada; Políticas Públicas; Programa Bolsa Família.

\section{ABSTRACT}

Conditional Cash Transfer (CCT) programs are of fundamental social importance to helping overcome situations of hunger and misery. Like all State policies, in addition to virtues, CCT-type programs also have limits of scope. This article, with an exploratory and deductive approach, sought to compare the trajectory and objectives of the Bolsa Familia Program (PBF). This stage was combined with the use of general statistical data from the region of Santa Maria to point out that the discussion of the validity of income complementation programs, such as the PBF, cannot take place in a way that

\footnotetext{
${ }^{1}$ Essa pesquisa foi produzida com fomento da Universidade Franciscana - UFN.

${ }^{2}$ Professor do Curso de Ciências Econômicas - Universidade Franciscana (UFN). Graduado em Economia pela Universidade Federal de Santa Maria (UFSM); Mestre em Economia (Unisinos); Doutor em Estudos Estratégicos Internacionais pela Universidade Federal do Rio Grande do Sul (PPGEEI/UFRGS). E-mail: rafael.poerschke@gmail.com

${ }^{3}$ Professora do Curso de História - Universidade Franciscana (UFN). Graduada Possui em História Licenciatura Plena pela Universidade Federal de Santa Maria (UFSM); Mestrado em Integração Latino Americana (UFSM); Doutora em Antropologia Social (PPGAS/UFRGS).E-mail: paulasbjardim@gmail.com

${ }^{4}$ Professora do Curso de Ciências Econômicas da Universidade Federal de Santa Maria. Graduada em Ciências Econômicas pela Universidade Federal de Santa Maria (UFSM); Mestra em Economia Rural pela Universidade Federal da Paraíba (UFPB); Doutora em Ciências Econômicas pela Universidade Estadual de Campinas (UNICAMP). Lider do Grupo de pesquisas do CNPQ Desenvolvimento, Governança, Inovação Social e Sustentabilidade (DISGOS). E-mail: rita.pauli@gmail.com
} 
it is disconnected from the reality of its target audience. The creation of a parameter, an index that captures inflationary fluctuations relevant to low-income families is notorious and is not predicted by the PBF. In countries of continental dimensions such as Brazil, we emphasize that the need for a periodic evaluation of the value of the PBF benefit would not be sufficient. This program also suffers from a regional perspective on the correction of the amounts paid as a benefit, since the costs of living and habits of the population covered by this type of program is very diverse regionally and culturally. In the end, if there is a difference, and no matter how small this deviation, only a greater adherence to the regional reality will be able to expand the conditions for a dignified life.

Keywords: Conditional Cash Transfer; Public Policy; Bolsa Familia Program.

\section{INTRODUÇÃO}

As políticas públicas são importantes aliadas do poder público no enfrentamento da desigualdade social na sociedade contemporânea. Primeiramente, possuem o propósito de ser uma medida de urgência para enfrentar situações de vulnerabilidade e fragilidade da população, também objetivam, a longo prazo, o progresso do desenvolvimento social, econômico e humano. Em especial, um Estado Democrático de Direito tem a pretensão de promover mudanças sociais, incremento de direitos e transformações na sociedade para torná-la mais justa e diminuir as desigualdades. Apesar de soar como um desejo audacioso, essa promessa se encontra na Constituição Federal Brasileira de 1988 na forma de lei. Além de promessa, essa diretriz constitucional é um meio de reconhecimento do Estado brasileiro da desigualdade social como um dos problemas centrais que acompanha a formação do Brasil e se atualiza constantemente.

Nesse contexto jurídico e histórico, a menção das políticas públicas pode ser vista como a forma que os agentes do Estados e da sociedade civil têm encontrado para tentar efetivar direitos previstos em lei. Como materializar o conjunto de direitos inspirados nos princípios dos Direitos Humanos estabelecidos no pós-segunda guerra? Qual o papel que essas políticas podem alcançar no processo tão vagaroso e precário de modernização do Estado brasileiro?

Assim, a fim de alcançar tantos sonhos e desejos convertidos em legislação, o conceito de políticas públicas é o ponto de partida de diversas áreas comprometidas com mudanças na sociedade brasileira e, portanto, abarca diversos entendimentos. Uma primeira interpretação remete à compreensão de que o governo é o promotor de ações que influenciam a vida dos cidadãos. Uma segunda definição de políticas públicas destaca o seu papel como resposta ao enfrentamento de questões públicas.

Conforme Celina Souza (2007), as políticas públicas simbolizam os meios de mobilizar o governo frente aos impasses da sociedade, e por isso elas estão no:

(...) campo do conhecimento que busca, ao mesmo tempo, colocar o 'governo em ação' e/ou analisar essa ação (variável independente) e, quando necessário, propor mudanças no rumo ou curso dessas ações (variável dependente). A formulação de políticas públicas constitui-se no 
estágio em que governos democráticos traduzem seus propósitos e plataformas eleitorais em programas e ações, que produzirão resultados ou mudanças no mundo real. (SOUZA, 2007, p. 69)

Todavia, independente do conceito de política pública, seu objetivo passa por dirimir os principais impasses que abatem as sociedades, e que atingem as camadas mais pobres e necessitadas da população. Diante disso, as políticas públicas são elaboradas por dois princípios básicos: a intencionalidade pública e o problema público. O primeiro elemento, intencionalidade pública, representa a “motivação para o estabelecimento de ações para tratamento ou para resolução de um problema”; já o segundo, problema público, refere-se à "diferença entre uma situação atual vivida (status quo) e uma situação ideal possível à realidade coletiva” (MIURA, 2015, p. 2).

Em suma, as políticas públicas são conduzidas por intermédio de questões que assolam uma determinada comunidade de indivíduos, concomitantemente com a urgência de elucidações e a implantação de um ideal de vida para a população. Com isso, o principal alvo das políticas públicas é a efetivação dos direitos fundamentais do cidadão, tendo como ponto de partida os problemas sociais e a busca pelo desenvolvimento humano.

A política pública é um meio utilizado pelo poder público para fortalecer as camadas mais pobres das sociedades, para fins de viabilizar o desenvolvimento e eliminar todas as formas de privações que estes enfrentam em seus cotidianos. Nesse sentido, quanto ao potencial desenvolvido pelas políticas públicas, destaca-se o entendimento de Zambam e Kujawa:

\footnotetext{
As políticas públicas têm esse duplo potencial de interferência no conjunto da sociedade. Primeiro, os seus investimentos atendem a demandas universais e, portanto, com capacidade de atender as necessidades básicas de uma ampla parcela da população vítima de variadas formas de exclusão que põe em risco a qualidade de vida de parte significativa da sociedade. Segundo, contemplam as ações prioritárias ou específicas, seja de grupos, seja individualmente, com o objetivo de atender situações particulares de exclusão, marginalização ou insegurança. (2017, p. 70).
}

Logo, a política pública, além de suprimir as privações individuais, contribui para a melhoria da sociedade e para a efetivação da democracia. Muitas vezes, os agentes públicos podem - ou não considerar evidências sobre o que funciona e por qual razão, ao decidirem pelo desenho de alguma etapa ou mecanismo a ser implementado. Como estudado no campo da economia política, os formuladores de políticas são, por vezes, submetidos a uma série de restrições e pressões que podem explicar falhas na adoção de políticas reconhecidamente eficazes.

A principal motivação para avaliar uma política pública é poder apontar ajustes no desenho de determinada etapa do programa social. Dada a complexidade que os programas do tipo Transferências Condicionadas de Renda (Conditioned Cash Transfers - CCTs) envolvem, ações coordenadas de avaliação são fundamentais para elevar a eficácia da política pública. Assim, por vezes, a crítica se divide em observar a fragilidade levantada do conjunto de obrigações assumidas pelos beneficiários diante dos mecanismos de controle, ou sobre a necessidade de ampliação da abrangência 
dos programas - seja pelo lado pecuniário (do orçamento ou da linha de pobreza considerada ${ }^{5}$ ) ou pelo número de famílias que recebem o benefício.

Portanto, a incorporação de evidências de avaliação e pesquisa no processo de decisão, não apenas aumenta a eficiência do programa, como poderá diminuir o desperdício de recursos em ações mal sucedidas. A sugestão de ajustes da trajetória de uma política pública aparece como garantia da eficiência no emprego dos recursos do erário. Esses ajustes são fundamentais para a aplicabilidade dos programas sociais, pois permitem às famílias a chance de elevar o seu bem estar e, até mesmo, superar $^{6}$ a situação de extrema pobreza (BANERJEE et al., 2015).

Nas palavras de Duflo (2007), dada a complexidade envolvida na criação e adoção de políticas públicas, muitos detalhes são deixados de lado ou nem foram previstos pelos modelos e teorias adotados. Pois, um modelo, ou desenho de mecanismos, desenvolvidos por "engenheiros", precisariam da ação de um "encanador" capaz de ajustar a medida ao mundo real a fim de melhorar o impacto final da política pública (DUFLO, 2007). Segundo Duflo, o "encanador" vai além do engenheiro, pois ele instala o mecanismo, observa o que acontece e pensa na correção/reparo que pode ser feito para melhorar seu resultado. Usando essa reflexão como uma metáfora, o trabalho da pesquisa na área das ciências sociais e aplicadas é análogo ao do engenheiro e pode incorporar, em parte, o trabalho do encanador à medida que interage com os agentes públicos envolvidos na execução das políticas.

Levando em conta os objetivos da aplicação de recursos públicos em benefícios assistenciais, depreende-se que a ampliação da abrangência de um programa ultrapassa a discussão se o número de famílias assistidas ou se o volume de recursos destinados seria suficiente. Uma política pública será igualmente ampliada se estudos técnicos desvelarem condições para um ajuste e/ ou correção das imperfeições dos mecanismos que tornam possível a assistência social. Portanto, a ausência de critérios e de estudos que apontem soluções, pela diferença na tributação ${ }^{7}$ e considerando a diferença nos hábitos de consumo da população, nos leva a questionar a necessidade de reajustes diferentes (compensadores) entre os mesmos beneficiários ${ }^{8}$. Nesse caso, discutiremos a viabilidade da criação ou presença de um indicador que mostre a perda de poder aquisitivo

\footnotetext{
${ }^{5}$ No Brasil, pelo Programa Bolsa Família (PBF), considera-se as famílias em situação de pobreza e de extrema pobreza as caracterizadas pela renda familiar mensal per capita de até R \$178,00 e R\$ 89,00, respectivamente (BRASIL, 2018). De acordo com as concepções de Amartya Sen, "a pobreza é conceituada como uma privação de capacidades básicas e não apenas como a expressão de baixa renda" (SEN, 2000, p.109). "Uma pessoa pobre é por definição alguém que não possui o suficiente para comer." (DUFLO, 2007, p. 4)

6 "Sair da linha de pobreza significava obter: um regime alimentar adequado, um certo nível de conforto, o desenvolvimento de papéis e de comportamentos socialmente adequados." (CRESPO; GUROVITZ, 2002, p.5)

${ }^{7}$ Tomamos o caso do Rio Grande do Sul, que tem uma alíquota de ICMS de $30 \%$ sobre o gás de cozinha (botijão de $13 \mathrm{Kg}$ ), enquanto em outros estados o imposto não ultrapassa dois dígitos.

${ }^{8}$ Aqui, embora o fim seja diferente, vale a analogia. Pois, as bolsas de estudo no exterior, pela Portaria $n^{\circ} 141$ da CAPES, variam de valor não só por causa da moeda local, elas também consideram uma diferenciação do custo de vida na cidade de destino dos pesquisadores que irão desenvolver estudos avançados no exterior.
} 
das famílias de baixa renda cadastradas no PBF. Então, o que pode ser dito sobre as famílias da Região Central do Rio Grande do Sul e indexadores com abrangência regional quando olhamos os dados de Santa Maria?

\section{POLÍTICAS PÚBLICAS: PROGRAMAS DE TRANSFERÊNCIA DE RENDA NAS AMÉRICAS}

Entendemos o Programa Bolsa Família (PBF) como um programa brasileiro que se caracteriza como sendo de Transferências de Renda Condicionadas, ou Conditioned Cash Transfers (CCTs). Os CCTs representam um modelo de política pública surgida nos anos 1990, e estão presentes em mais de 60 países. Os programas de CCTs são os vetores que conectam as redes de proteção social, definidas como intervenções não contributivas, às famílias para auxiliar os indivíduos a lidar com a pobreza crônica, a desnutrição e a vulnerabilidade social (BANCO MUNDIAL, 2018).

Entre os mais antigos das Américas, destaca-se o programa dos Estados Unidos, conhecido popularmente como Food Stamp. Os "selos" para compra de alimentos atualmente fazem parte do Supplemental Nutrition Assistance Program (SNAP), que teve como predecessor o Food Stamp Program, de 1939, entre outros programas que foram implementados nos anos 1960. O programa foi desenhado para garantir uma oferta adequada de alimentos nas cidades após o processo de migração causado pela Grande Depressão. Os recursos do programa são parte do orçamento do Departamento de Agricultura (United States Department of Agriculture), e atualmente totalizaram US\$ 68 bilhões, cobrindo quase 40 milhões de beneficiários em 2018 (USDA, 2019).

Entre os diferentes programas de transferência condicionada de renda na América Latina, destacamos o Programa Oportunidades, do México (1997-2014), que está entre os mais antigos, enquanto o Programa Chile Solidário (2002-2017), do Chile, é o programa de maior amplitude. Além disso, a Argentina possuía um programa chamado Jefes y Jefas de Hogar Desocupados (2002-2005), cujo benefício era de $\$ 150,00$ (pesos argentinos) e abrangia aproximadamente 1,4 milhões de pessoas em 2006 (NASCIMENTO; REIS, 2009).

O programa mexicano oferecia como benefício um valor de $\$ 189,00$ (pesos mexicanos) por família para fins alimentícios, além de \$250,00 para os idosos, e uma bolsa de estudos que podia variar de $\$ 120,00$ a $\$ 760,00$ por estudante, com um limite de até $\$ 1.855,00$ por família, com contrapartidas exigidas referentes à saúde e educação (NASCIMENTO; REIS, 2009). Porém, assim como ocorreu com o Programa Bolsa ${ }^{9}$ Família, o Programa Oportunidades e o Programa de Apoyo Alimentario (PAL) foram unificados em 2010 (CEPAL, 2019). Atualmente, existe o Programa Prospera, criado em 2014, que deu sucessão ao Programa Oportunidades, que visa prover auxílio direcionado à

\footnotetext{
${ }^{9}$ Vale lembrar que no governo FHC houve a criação de diversos programas sociais, como o bolsa-escola, o vale-gás e o bolsa-alimentação. Todos estavam ligados a diferentes ministérios e acabram sendo unificados nos moldes da medida que implantou o Programa Bolsa Família.
} 
alimentação, saúde e educação às famílias com recursos financeiros precários. Há transferências bimestrais, e suas contrapartidas são igualmente a saúde, a educação e a nutrição (MÉXICO, 2014).

Por outro lado, o programa chileno tinha como benefício US\$330,00 (dólares), enquanto entre as condicionalidades aparecem compromissos com a saúde, educação, habitação, trabalho, dentre outros. O Programa Chile Solidário abrangia em torno de 247.677,00 famílias segundo o Ministerio de Desarrollo Social y Familia (MÉXICO, 2014), o que alcançava 1,38\% da população chilena. A partir de 2014, o programa passou a ser complementado pelo Aporte Familiar Permanente, que consiste no valor de $\$ 46.374,00$ (pesos) que é conferido todo mês de março para famílias de baixa renda.

O programa argentino Jefes y Jefas (2002-2005) era destinado a crianças menores de 18 anos, pessoas com necessidades especiais e mulheres grávidas, com até uma transferência mensal por família. Suas contrapartidas eram relacionadas à saúde, educação e emprego, e seu órgão responsável era o Ministerio del Trabajo, Empleo y Seguridad Social (ARGENTINA, 2002). Existe, desde 2009, o Programa Asignación Universal por Hijo para Protección Social (AUH), cujos beneficiados são crianças menores de 18 anos, desempregados ou trabalhadores informais, trabalhadores domésticos com rendimento menor do que o salário mínimo, e pessoas envolvidas nos programas Hacemos Futuro, Manos a la Obra e outros. O valor geral em 2018, de acordo com CEPAL (2018), era de $\$ 1.816,00$ pesos por pessoa, sendo que pode haver, no máximo, 5 beneficiários por família (ARGENTINA, 2009).

Na América Latina, o gasto com programas sociais cresceu substancialmente ao longo da última década. Brasil e México abriram caminho para programas desse genêro, e por meio de uma externalidade em rede, essa ideia se expandiu para os países da região e mundo afora (BANCO MUNDIAL, 2018, p. 37). Conforme suas diretrizes, o PBF é uma intervenção que procura reduzir a insuficiência de renda das famílias pobres e/ou vulneráveis por meio de transferências regulares de recursos mediante condicionalidades - como a frequência à escola das crianças e adolescentes que vivem no mesmo domicílio da família; e o cumprimento da agenda básica de saúde das crianças, gestantes e nutrizes (BRASIL, 2004).

Sem tentar estabelecer qualquer relação de causa e efeito para o Brasil, Hoffmann (2013) mostrou que, de 2004 a 2009, a renda real per capita da mediana aumentou mais de $40 \%$ e a escolaridade cresceu em dois anos. Assim, com o substancial aumento da renda, e com crescimento mais intenso da renda dos relativamente mais pobres, "poderia se prever a queda na incidência de insegurança alimentar. Isso efetivamente ocorre para a insegurança alimentar moderada (cuja incidência cai de $12,3 \%$ para $6,5 \%$ dos domicílios) e para a insegurança alimentar grave (cuja incidência cai de 6,3\% para 4,9\% dos domicílios)" (HOFFMANN, 2013, p. 219).

O resultado positivo dos anos 2000 coloca o PBF como uma política pública de Estado. O escrutínio dos diferentes mecanismos que compõem o programa são parte do processo de avaliação que visa identificar possíveis ajustes de trajetória a fim de melhorar a distribuição de renda - e dos 
benefícios. O Programa Bolsa Família, durante sua existência, passou por uma série de avanços ${ }^{10}$ e/ou ajustes $^{11}$ que não foram capazes de alterar a natureza de seus objetivos.

Em 15 anos de PBF, os benefícios ${ }^{12}$ foram reajustados em apenas sete oportunidades. Se aplicássemos a mesma regra dos benefícios sociais previdenciários, que faz uso do Índice Nacional de Preços ao Consumidor ${ }^{13}$ (INPC), teríamos, de outubro de 2003 a maio de 2018, pouco mais de 122\% de inflação acumulada. O benefício básico passou dos R \$50,00, valor à época do lançamento do PBF, para os atuais $\mathrm{R} \$ 89,00$ (ver Tabela que segue).

Tabela 01 - Lista de todos os reajustes, em Reais (R\$), dos benefícios do Programa Bolsa Família.

\begin{tabular}{lccc}
\hline \multicolumn{1}{c}{ Decreto / Medida Provisória } & Básico & Crianças & Adolescente \\
\hline $\begin{array}{l}\text { 1) Medida Provisória } \mathrm{n}^{\circ} \text { 132, de 20.10.2003 } \\
\text { (Convertida na Lei } \mathrm{n}^{\circ} \text { 10.836, de 9.1.2004) }\end{array}$ & $\mathrm{R} \$ 50,00$ & $\mathrm{R} \$ 15,00$ & - \\
\hline 2) Decreto $\mathrm{n}^{\circ}$ 6.157, de 16.07.2007 & $\mathrm{R} \$ 58,00$ & $\mathrm{R} \$ 18,00$ & - \\
\hline $\begin{array}{l}\text { 3) Medida Provisória } \mathrm{n}^{\circ} \text { 411, de 28.12.2007 } \\
\text { (Convertida na Lei } \mathrm{n}^{\circ} \text { 11.692, de 10.06.2008) }\end{array}$ & $\mathrm{R} \$ 58,00$ & $\mathrm{R} \$ 18,00$ & $\mathrm{R} \$ 30,00$ \\
\hline 4) Decreto $\mathrm{n}^{\circ}$ 6.491, de 28.06.2008 & $\mathrm{R} \$ 62,00$ & $\mathrm{R} \$ 20,00$ & $\mathrm{R} \$ 30,00$ \\
\hline 5) Decreto $\mathrm{n}^{\circ}$ 6.917, de 30.07.2009 & $\mathrm{R} \$ 68,00$ & $\mathrm{R} \$ 22,00$ & $\mathrm{R} \$ 33,00$ \\
\hline 6) Decreto $\mathrm{n}^{\circ}$ 7.447, de 01.03 .2011 & $\mathrm{R} \$ 70,00$ & $\mathrm{R} \$ 32,00$ & $\mathrm{R} \$ 38,00$ \\
\hline 7) Decreto $\mathrm{n}^{\circ}$ 8.232, de 30.04.2014 & $\mathrm{R} \$ 77,00$ & $\mathrm{R} \$ 35,00$ & $\mathrm{R} \$ 42,00$ \\
\hline 8) Decreto $\mathrm{n}^{\circ}$ 9.396, de 30.05.2018 & $\mathrm{R} \$ 89,00$ & $\mathrm{R} \$ 41,00$ & $\mathrm{R} \$ 48,00$ \\
\hline
\end{tabular}

Fonte: Elaboração própria (2020).

Não é preciso ser matemático para perceber que os aumentos repassados não foram suficientes para cobrir a inflação do período. Se assim o tivessem, o benefício deveria estar pagando pouco mais de R\$ 100,00. Para ser mais exato, a correção do benefício entre 2003 e 2018 foi de 78\%, ficando muito abaixo da inflação do período.

Os dados da tabela que segue (Tabela 02) ilustram o descompasso entre o poder aquisitivo de quem depende do PBF e aqueles que recebem benefícios previdenciários. No governo Dilma, a Lei $n^{\circ} 12.832 / 2011$ indexou os reajustes do salário mínimo ${ }^{14}$ à variação do INPC do ano anterior, com garantia de ganho real atrelado ao crescimento do produto interno bruto dos dois anos anteriores. O salário mínimo, que é usado como um limite inferior para aposentadorias, pensões e pagamento do ${ }^{10}$ Em 2007, houve a inclusão do benefício variável vinculado ao adolescente (BVJ), para jovens entre 16 e 17 anos de famílias com renda por pessoa de até R \$ 178, limitado a dois benefícios por família.

${ }^{11}$ Entre elas, destaca-se o aperfeiçoamento das rotinas de verificação de inconsistências cadastrais, visando a melhoria da qualidade das informações do Cadastro Único. Mais recentemente, o Ministério da Cidadania, por meio da Instrução Operacional Conjunta $n^{\circ}$ 02/SAGI/ Secretaria Nacional de Renda de Cidadania (SENARC), alterou procedimentos, dando início a uma nova ação de atualização cadastral em 2019.

${ }^{12}$ Aqui, entendemos como benefícios os valores pagos como o benefício básico, para crianças e adolescentes nas famílias. ${ }^{13}$ O INPC mede a inflação para famílias com renda de até cinco salários mínimos.

${ }^{14}$ As aposentadorias e pensões superiores a um salário mínimo são reajustadas pelo INPC, atendendo ao mandamento constitucional do art. $7^{\circ}$, inciso IV, que estabelece como direito dos trabalhadores urbanos e rurais "salário mínimo, fixado em lei, nacionalmente unificado, capaz de atender a suas necessidades vitais básicas e às de sua família com moradia, alimentação, educação, saúde, lazer, vestuário, higiene, transporte e previdência social, com reajustes periódicos que lhe preservem o poder aquisitivo, sendo vedada sua vinculação para qualquer fim” (BRASIL,1988). 
BPC (Benefício de Prestação Continuada) - destinado a idosos e incapacitados de baixa renda, teve um expressivo ganho real nos últimos anos.

Se observamos a evolução do INPC, entre o último salário mínimo estabelecido na era FHC e o atual salário mínimo da gestão Bolsonaro, a inflação acumulada não ultrapassou 200\% (quarta coluna da última linha da Tabela 02). Por outro lado, o salário mínimo nesse mesmo período cresceu acima da inflação, e acumulou uma valorização de quase 420\% (quarta coluna da última linha da Tabela 02). Também, é possível notar que grande parte desse aumento real se deve à política de valorização do salário mínimo empregada ao longo da gestão PT (Partido dos Trabalhadores). Ainda, um olhar mais cuidadoso revela a desaceleração desses ganhos no deccorer do tempo, tal reversão vem sendo motivada pela crise orçamentária do erário - descrita na Medida Provisória n 916/2019 do governo Bolsonaro.

Tabela 02 - Reajustes do Salário Mínimo e a inflação medida pelo INPC (2002-2020).

\begin{tabular}{|c|c|c|c|c|}
\hline & \multicolumn{2}{|c|}{ Reajustes do Salário Mínimo } & \multirow{2}{*}{$\begin{array}{c}\text { INPC } \\
\text { Número-Índice }\end{array}$} & \multirow{2}{*}{$\begin{array}{c}\text { Salário Mínimo } \\
\text { Valor Nominal }\end{array}$} \\
\hline & Reajuste & Medida & & \\
\hline $\begin{array}{c}\text { FHC } \\
(1995-2002)\end{array}$ & $\begin{array}{l}\text { Último } \\
\text { reajuste }\end{array}$ & $\begin{array}{c}\text { Medida Provisória } \mathrm{n}^{\mathrm{o}} 35 \\
\text { de } 27.03 .2002\end{array}$ & $\begin{array}{l}\operatorname{mar} / 2002: 1.867,01 \\
\mathrm{abr} / 2002: 1.879,71\end{array}$ & $\mathrm{R} \$ 200,00$ \\
\hline $\begin{array}{c}\text { LULA } \\
(2003-2010)\end{array}$ & $\begin{array}{l}\text { Primeiro } \\
\text { reajuste } \\
\text { Último } \\
\text { reajuste }\end{array}$ & $\begin{array}{l}\text { Medida Provisória } \mathrm{n}^{\circ} 116, \\
\text { de } 02.04 .2003 \\
\text { Acumulado } \\
\text { Medida Provisória } \mathrm{n}^{\circ} \text { 516, } \\
\text { de } 30.12 .2010 \\
\text { Acumulado }\end{array}$ & $\begin{array}{c}\operatorname{mar} / 2003: 2.213,17 \\
\operatorname{abr} / 2003: 2.243,71 \\
\operatorname{mar} / 2002-\operatorname{mar} / 2003: \mathbf{2 0 , 1 8 \%} \\
\operatorname{dez} / 2010: 3.297,76 \\
\text { jan/2011:3.328,76 } \\
\text { abr/2003 - dez/2011: } \mathbf{5 0 , 4 1 \%}\end{array}$ & $\begin{array}{c}\text { R\$ 240,00 } \\
\text { Reajuste: } \mathbf{2 0 \%} \\
\text { R\$ 540,00 }\end{array}$ \\
\hline $\begin{array}{c}\text { DILMA } \\
(2011-2016)\end{array}$ & $\begin{array}{l}\text { Primeiro } \\
\text { reajuste }\end{array}$ & $\begin{array}{l}\text { Lei } \mathrm{n}^{\circ} 12.832, \\
\text { de } 25.02 .2011 \\
\text { Acumulado } \\
\text { Decreto } \mathrm{n}^{\circ} 8.618, \\
\text { de } 29.12 .2015 \\
\text { Acumulado }\end{array}$ & $\begin{array}{c}\text { fev/2011:3.346,74 } \\
\operatorname{mar} / 2011: 3.368,83 \\
\text { jan/2011 - fev/2011: } \mathbf{1 , 4 9 \%} \\
\text { dez/2015:4.635,75 } \\
\text { jan/2016:4.705,45 } \\
\operatorname{mar} / 2011-\operatorname{dez} / 2015: \mathbf{3 8 , 5 2 \%}\end{array}$ & $\begin{array}{c}\mathrm{R} \$ 545,00 \\
\text { Reajuste: } \mathbf{1 \%} \\
\mathrm{R} \$ 880,00 \\
\text { Reajuste: } \mathbf{6 1 , 4 7 \%}\end{array}$ \\
\hline $\begin{array}{c}\text { TEMER } \\
(2016-2018)\end{array}$ & $\begin{array}{l}\text { Primeiro } \\
\text { reajuste }\end{array}$ & $\begin{array}{l}\text { Decreto } \mathrm{n}^{\circ} 8.9848, \\
\text { de } 29.12 .2016 \\
\text { Acumulado } \\
\text { Decreto } \mathrm{n}^{\circ} 9.255, \\
\text { de } 29.12 .2017 \\
\text { Acumulado }\end{array}$ & $\begin{array}{c}\text { dez/2016:4.940,78 } \\
\text { jan/2017:4.961,53 } \\
\text { jan/2016 - dez/2016: } \mathbf{6 , 5 8 \%} \\
\text { dez/2017:5.042,92 } \\
\text { jan/2018:5.054,52 } \\
\text { jan/2017 - dez/2017: } \mathbf{2 , 0 7 \%}\end{array}$ & $\begin{array}{c}\text { R\$ 937,00 } \\
\text { Reajuste: } \mathbf{6 , 4 8 \%} \\
\text { R\$ 945,00 }\end{array}$ \\
\hline $\begin{array}{c}\text { BOLSONARO } \\
(2019-)\end{array}$ & $\begin{array}{l}\text { Primeiro } \\
\text { reajuste }\end{array}$ & $\begin{array}{l}\text { Decreto } n^{\circ} 9.661 \text {, } \\
\text { de } 01 / 01 / 2019 \\
\text { Acumulado } \\
\text { Lei } n^{\circ} 14.013 \text {, } \\
\text { de } 10.06 .2020 \\
\text { Acumulado }\end{array}$ & $\begin{array}{c}\text { dez/2018:5.216,08 } \\
\text { jan/2019:5234,86 } \\
\text { jan/2018 - dez/2018: } \mathbf{3 , 4 3 \%} \\
\text { dez/2019:5449,84 } \\
\text { jun/2020: } 5.469,41 \\
\text { jan/2019 - jun/2020: } \mathbf{4 , 8 6 \%}\end{array}$ & $\begin{array}{c}\text { R\$ 998,00 } \\
\text { Reajuste: } \mathbf{5 , 6 1 \%} \\
\text { R\$ 1.039,00 } \\
\text { Reajuste: } \mathbf{4 , 1 1 \%}\end{array}$ \\
\hline & Acumulado & $\begin{array}{l}\text { (março de } 2002 \text { - } \\
\text { junho de 2020) }\end{array}$ & $\begin{array}{l}\text { Inflação } \\
192,95 \%\end{array}$ & $\begin{array}{c}\text { Reajustes } \\
419,5 \%\end{array}$ \\
\hline
\end{tabular}

Fonte: Elaboração própria (2020). 
Mas, mesmo o INPC, que foi criado inicialmente com o objetivo de orientar os reajustes de salários dos trabalhadores, não seria uma boa base de comparação para o acompanhamento da perda de poder aquisitivo da população-alvo do PBF. Vale lembrar que o INPC abrange as famílias com rendimentos mensais compreendidos entre 1 (um) e 5 (cinco) salários-mínimos. Ainda que a comparação fosse sobre um salário mínimo, ainda estaríamos falando de dados viesados. Se estivéssemos corrigindo os valores repassados pelo governo com o INPC, as famílias da região de Porto Alegre deveriam saber que a Região Sudeste responde por quase 40\% da variação desse indicador. Em outras palavras, a recomposição de valores em Porto Alegre pelo INPC nacional teria por base a inflação do Sudeste e de outras regiões do Brasil, pois os índices agregados de inflação têm uma abrangência regional - pesando mais a Região Sudeste do país, o que tornaria a adoção de um indicador sem critério preocupante.

Se ainda não existe um deflator ${ }^{15}$ ou indexador relacionado, não resta dúvida quanto à importância que o programa tem para as famílias assistidas. Contudo, sobram críticas sobre as alterações na linha das famílias elegíveis, no entanto, os estudos sobre estabilidade do poder de compra dos benefícios são poucos. Mesmo que o principal debate na literatura seja sobre a linha da pobreza ${ }^{16}$ e a atualização desses valores, conforme Schwartzman (2003), o presente artigo discute as vantagens advindas da criação de critérios, a necessidade de uma periodicidade ou cesto específíco para o reajuste aplicável no nível municipal ou na agregação padrão das Regionais do dataSUS. Mas, seria o atual mecanismo de majoração dos benefícios suficiente, isto é, seria ele garantia de eficácia no atentimento das necessidades do público a que se destina?

De outro modo, é importante investigar se o PBF, que assiste a mais de 16 mil famílias na região Central do Rio Grande do Sul, tem conseguido garantir a estabilidade do poder aquisitivo das famílias beneficiadas na região. Nossa preocupação é com a perda do poder aquisitivo (ou não) das famílias em função da ausência de um critério claro para reajustes períodicos dos benefícios do PBF.

\footnotetext{
${ }^{15}$ Lei no 10.836 , de 9 de janeiro de 2004. Artigo $1^{\circ} \S 6^{\circ}$ “'Os valores dos benefícios e os valores referenciais para caracterização de situação de pobreza ou extrema pobreza de que tratam os $\S \S 2^{\circ}$ e $3^{\circ}$ poderão ser majorados pelo Poder Executivo, em razão da dinâmica socioeconômica do País e de estudos técnicos sobre o tema, atendido o disposto no parágrafo único do art. $6^{\circ}$."

${ }^{16}$ Paiva et al. (2018), avaliaram ajustes no PBF, e entre as críticas destacadas, apenas comentaram sobre os benefícios do Bolsa Família e a necessidade de atualização periódica. Contudo, a avaliação foi voltada mais para as linhas de pobreza e extrema pobreza e sua falta de reajuste durante períodos relativamente longos. A última atualização da linha de referência se deu no governo Temer, pelo Decreto n ${ }^{\circ}$ 9.396, de 30 de maio de 2018. Sendo assim, o PBF passou a atender as famílias em situação de pobreza e de extrema pobreza, "caracterizadas pela renda familiar mensal per capita de até $\mathrm{R} \$ 178,00$ (cento e setenta e oito reais) e R $\$ 89,00$ (oitenta e nove reais), respectivamente."
} 
No que tange aos dados empíricos, o município de Santa Maria tem a maior população e renda da Região Central e, conforme os dados do dataSUS ${ }^{17}$ (2019), em 2018, a cidade ${ }^{18}$ respondeu por $31 \%$ das 16.480 famílias beneficiárias pelos recursos do $\mathrm{PBF}^{19}$.

\section{PBF NO MUNICÍPIO: UM RETRATO DE SANTA MARIA EM 2019}

A consulta ao Cadastro Único (CadÚnico) para Programas Sociais do Ministério do Desenvolvimento Social e Agrário (2018) revela que, no Rio Grande do Sul, 928.310 famílias estavam inscritas no Programa em agosto de 2018. Do total de famílias, segundo o MDSA (2018):

- $\quad 33,42 \%$ auferiam renda per capita familiar mensal de até $\mathrm{R} \$ 85,00$;

- $\quad 14,39 \%$ apresentavam renda per capita familiar entre R \$ 85,01 e R \$ 170,00;

- 24,37\% auferiam renda per capita familiar entre R\$170,01 e meio salário mínimo; e

- $\quad 27,82 \%$ recebiam renda per capita acima de meio salário mínimo.

Desse quase um milhão famílias gaúchas inscritas no CadÚnico, uma parcela significativa é formada pelas 363.067 famílias beneficiárias do Programa Bolsa Família (PBF). De acordo com o MDSA (2018), as famílias recebem benefícios com valor médio de R \$ 170,74 e o valor total transferido pelo governo federal em benefícios às famílias atendidas no estado alcançou R \$ 61.990.770,00 no mês de agosto de 2018. Dentre o público registrado no CadÚnico à época no estado, 2.983 eram quilombolas, 5.794 eram indígenas, outros 200 estavam cadastrados no grupo dos extrativistas, 2.479 pescadores artesanais, 1.134 ribeirinhos, 8.175 famílias de catadores de materiais recicláveis, 38.526 agricultores familiares e 5.830 famílias assentadas da Reforma Agrária (MDSA, 2018).

Dessas mais de 360 mil famílias, 16.480 recebem benefícios no PBF na Regional de Santa Maria, e somente no município de Santa Maria, o número de benefícios pagos chegou a 6.121 (MDS, 2019). Ao todo, a cidade de Santa Maria recebeu R\$ 1.001.376,00 que beneficiou mais de 7.680 crianças na cidade.

\footnotetext{
${ }^{17} \mathrm{O}$ dataSUS recebe dados de inscritos no Bolsa Família, portanto é o sistema de informação que apoia os serviços de acompanhamento às famílias beneficiadas pelo Programa. Assim como o Cadastro Único, ele possibilita o armazenamento de dados relativos ao cumprimento das condicionalidades e acompanhamento nutricional dos membros das famílias no atendimento nas diversas áreas da unidade. Permite o acompanhamento da avaliação nutricional das fases do ciclo de vida de crianças menores de 7 anos e mulheres entre 10 e 60 anos.

${ }^{18}$ Pelos dados do dataSUS, que considera a Regional de Santa Maria com 32 municípios: Agudo, Cacequi, Capão do Cipó, Dilermando de Aguiar, Dona Francisca, Faxinal do Saturno, Formigueiro, Itaara, Itacurubi, Ivorá, Jaguari, Jari, Júlio de Castilhos, Mata, Nova Esperança do Sul, Nova Palma, Paraíso do Sul, Pinhal Grande, Quevedos, Quevedos, Restinga Seca, Santa Maria, Santiago, São Francisco de Assis, São João do Polisene, São Martinho da Serra, São Pedro do Sul, São Sepé, São Vicente do Sul, Silveira Martins, Toropi, Unistalda, Vila Nova do Sul.

${ }^{19}$ No decorrer da investigação, houve uma possibilidade de expansão de informações sobre o programa devido a uma cooperação acertada com a Secretaria Municipal de Desenvolvimento Social e assistentes sociais responsáveis pelo Cadastro Único na cidade.
} 
Desta feita, o PBF assegura alento contrapondo-se a um modelo concentrador de riquezas e gerador de mazelas sociais, na tentativa de garantir a geração e distribuição da renda entre famílias que estão (ou poderiam estar) em situação de vulnerabilidade. Contudo, dado o modelo atual de atualização de valores, o PBF não garante a manutenção do poder de compra da população assistida de maneira uniforme ao longo do território abrangido. Buscamos entender a pobreza e a situação de vulnerabilidade de maneira a considerar que a desigualdade não pode ser combatida sem que haja um esforço em compreender as questões e as necessidades regionais.

Portanto, não bastaria o desenvolvimento de políticas públicas voltadas a públicos específicos. A política pública para ser bem implementada precisa de ajustes e a inclusão de novos mecanismos que devem fazer a diferença. A desobstrução desse caminho, entre as famílias cadastradas em programas sociais e o agente público, só pode ocorrer com pesquisa interessada a debruçar um olhar mais cuidadoso sobre o poder aquisitivo que as famílias experimentam. É preciso garantir avaliações que abram espaço para a discussão de ajustes que tornem a aplicação dessa política mais ampla e eficaz, indo além do que está previsto na lei 10.836/2004.

\section{DESCRITIVO DA REALIDADE SOCIOECONÔMICA DE SANTA MARIA (RS)}

Santa Maria é um município localizado na região central do estado do Rio Grande do Sul, com extensão territorial de $1.788,12 \mathrm{~km}^{2}$ e população de 261.031 habitantes, dos quais $47,36 \%$ são homens e 52,64\% são mulheres. Aproximadamente 94,9\% dos habitantes do município vivem no meio urbano (IBGE, 2010). É regionalmente reconhecida como "cidade cultura," pela forte presença de instituições de ensino e pesquisa, apresentando Índice de Desenvolvimento Humano Municipal (IDHM, 2010) superior a 0,78 (VIEIRA et al., 2018). Apesar da presença de diversas instituições educacionais, o município apresenta problemas socioeconômicos de diversas ordens.

Em especial, cita-se a incidência de pobreza, que aflige 25,26\% de seus habitantes (IBGE, 2000) (OLIVEIRA et al., 2018). Segundo dados do IBGE (2018), 30,5\% da população santa-mariense apresenta rendimento nominal mensal per capita de até meio salário mínimo e, para o ano de 2016, 70,6\% da população santa-mariense era considerada potencialmente ativa. 
Figura 1 - Mapa da Região Central do Rio Grande do Sul

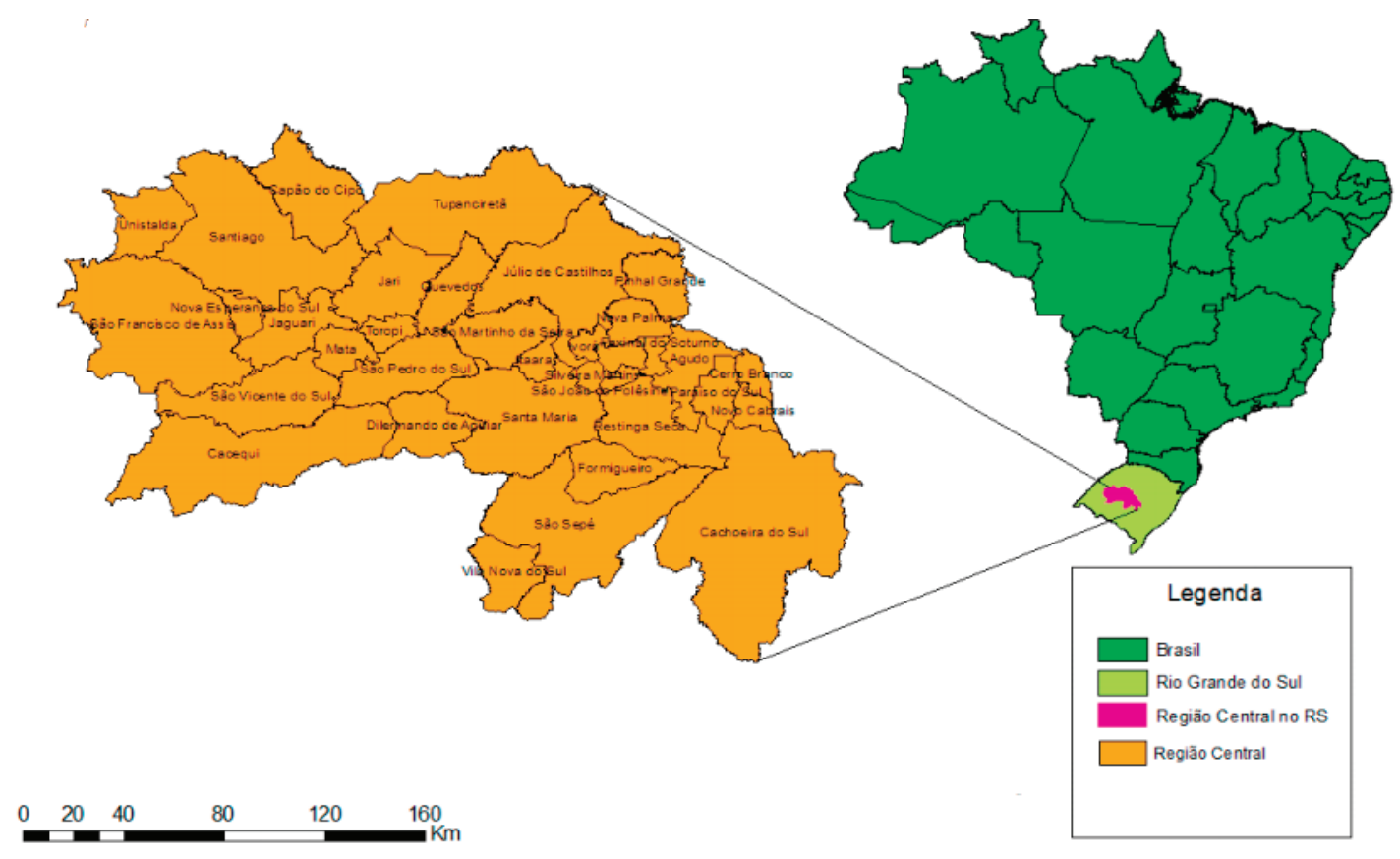

Fonte: IBGE (2015), adaptado pelos autores.

Estatísticas publicadas pelo IBGE (2010) indicam que a renda domiciliar per capita era de R\$ 1.108,07 em Santa Maria. Os setores de serviços e comércio foram responsáveis pela maior parte da geração de riqueza, juntos eles responderam por cerca de 70,9\% do Valor Agregado (VA) do município em 2015. No mesmo ano, a Administração Pública representou 15,9\% do VA, enquanto a agropecuária e a indústria totalizaram 13,2\% do VA (IBGE, 2018). Ademais, o Índice de Gini20 permaneceu praticamente estático entre 2000 e 2010, pois passou de 0,56 para 0,557 na última estatística publicada pelo Atlas Brasil. Com isso, pode-se inferir que a desigualdade social está presente no referido município.

Em 2018, 49.358 pessoas estavam vinculadas ao Cadastro Único para Programas Sociais do Governo Federal (Cadastro Único) em Santa Maria, mas cerca de 21.639 famílias cadastradas (24\%) auferiram renda per capita mensal de até R\$ 89,00 (SAGI, 2019). Quanto ao Programa Bolsa Família, a cidade tem cadastradas $6.121^{21}$ famílias beneficiárias, sendo que 4.587 recebem o benefício básico (SAGI, 2019). Vale ressaltar que aproximadamente um terço desses benefícios (2.076) da cidade são pagos na forma do Benefício de Superação da Extrema Pobreza (BSP).

Esquadrinhando esse cadastro por grupos étnicos no Relatório de Infomações Sociais (SAGI, 2020), observa-se que esse subgrupo não representa a maioria dos benefícios concedidos na cidade. Entre famíliais ribeirinhas (1), indígenas (34) e quilombolas (14), o número de benefícios concedidos pelo PBF não passa de 50. O mesmo acontece para os grupos do meio rural, no qual o maior número de famílias beneficiadas vem da agricultura familiar (16). Portanto, o benefício da cidade de Santa

\footnotetext{
${ }^{20} \mathrm{O}$ Índice de Gini varia entre 0 e 1, portanto, quanto mais próximo de 0 , melhor será a distribuição de renda.

${ }^{21}$ Segundo dados de fevereiro de 2020 (SAGI, 2020), esse número havia subido para 6.234 famílias.
} 
Maria se concentra nos grupos em situações conjunturais, uma vez que 347 famílias de catadores de material reciclado, seguido da população de moradores de rua (107).

\section{LIMITES DE UM PROGRAMA DEPENDENTE DO PODER EXECUTIVO}

Entre as maiores fragilidades do PBF, podemos destacar a ausência de um indicador oficial para indexar e garantir a recomposição do poder de compra ao benefício social. Se os reajustes concedidos pelo Instituto Nacional do Seguro Social (INSS) não podem desrespeitar o parágrafo $4^{\circ}$, do artigo 201, da Constituição Federal, que garante a manutenção do valor real do benefício e tem o Índice Nacional de Preços ao Consumidor (INPC) como parâmetro para reajustes, o Programa Bolsa Família, por sua vez, tem sido reajustado ao longo dos últimos governos por meio de Decretos ou edição de Medidas Provisórias. No PBF, os reajustes acontecem sem a adoção de um indicador de referência ${ }^{22}$ ou mesmo a garantia de uma periodicidade.

Sua eficácia regional deve ser igualmente questionada, isto é, sendo único o valor para todo um território como o brasileiro, a principal hipótese consiste em aceitar que o reajuste do benefício é necessário, mas muitas vezes não é o suficiente (e deveria ser compensado) em função da diversidade presente entre os grupos socioeconômicos abrangidos. Essa diferença na racionalidade do padrão de consumo entre estratos de renda da extremidade inferior é reconhecida por Snyder (1961), Michael (1979), Hagemann (1982), Duflo (2006a), Duflo (2006b) e Banerjee e Duflo (2007). No Brasil, Graziano da Silva ${ }^{23}$ (1996) e Paiva et al. (2018) também reconhecem essa característica nos interlocutores dessa pesquisa. Portanto, torna-se fundamental discutir e avaliar o mecanismo de indexação para os benefícios do programa PBF à luz de outras experiências bem sucedidas na América Latina. Tal constatação ganhou voz no Projeto de lei 6072/19, que propõe reformular os benefícios financeiros do Programa Bolsa Família a fim de assegurar a atualização anual dos recursos e dos valores referenciais para caraterização da situação de pobreza e extrema pobreza ${ }^{24}$.

A conexão entre gestores de órgãos federais, estaduais, municipais e instituições civis possibilitou uma rede estável de tutela e desenvolvimento social, que promove a garantia de condições de sobrevivência. Esse mecanismo de gestão compartilhada permite o funcionamento do programa PBF, e, portanto, foi essa linha que levou aos questionamentos motivadores de pesquisa.

\footnotetext{
${ }^{22}$ Não consta nada na publicação da Lei que criou o PBF sobre uma regra adotada para tal concessão.

${ }^{23}$ Nas palavras de José Graziano (1996), o consumo dessas famílias, em função da renda, se restringe a um leque muito pequeno de itens. Sobretudo, o autor destaca que para o baixa renda não existem bens inferiores uma vez que ele não consome a quantidade ideal de alimentos. Sendo assim, aumentos de renda (complementação com recursos do PBF) devem ser revertidos quase que exclusivamente no aumento de consumo de alimentos básicos, como arroz e feijão. Para Banerjee e Duflo (2007), embora cada centavo conte, entre 56 e 74\% vão para alimentação.

${ }^{24}$ A proposta surgiu independente e ao longo da presente pesquisa, contudo até a publicação desse artigo, o PL permanecia em apreciação em função dos rumores de um novo programa de distribuição de renda do governo Bolsonaro, chamado Renda Brasil. Com relação ao programa Renda Brasil, não havia muitas informações até a finalização do presente artigo.
} 
Doravante, um indicador fidedigno deve ser pensado numa estrutura semelhante à cesta básica de alimentos. Embora exista um projeto de extensão do Cálculo do Índice de Custo de Vida em Santa $\operatorname{Maria}^{25}$ (ICVSM), que já está em curso desde 2006, e contou com o apoio da Prefeitura Municipal ${ }^{26}$ à época, ainda não temos a correta aferição da cesta básica de consumo compatível com os beneficiários do PBF. Pois, a metodologia para cálculo do custo de vida em Santa Maria teve como referência o Índice de Preços ao Consumidor Amplo (IPCA) e o Índice Nacional de Preços ao Consumidor (INPC), divulgados pelo Instituto Brasileiro de Geografia e Estatística (IBGE).

Os resultados mensais do cálculo do ICVSM são demandados pela comunidade santa-mariense e publicizados na mídia local. Na medida em que os índices de preços são números-índices agregados e representam uma determinada cesta de produtos, sua variação irá medir, portanto, a variação média dos preços dos produtos dessa cesta. Na cidade de Santa Maria, o cálculo do Índice de Custo de Vida $^{27}$, tem como base dezembro de 2005 (CANABARRO et al., 2013). Contudo, o ICVSM não abrange o custo de vida das famílias de baixa renda, não sendo assim elegível como um termômetro ideal.

Finalmente, não temos uma resposta para apontar dentre os indicadores existentes, qual seria o mais fidedigno para equilibrar o poder de compra do benefício do PBF, mas estamos convíctos de que o programa precisa de ajustes. Seria interessante a introdução de um instrumento constitucional, com poder de garantir os direitos fundamentais do público-alvo do PBF, através da mudança na forma pela qual os reajustes dos beneficios são feitos, além da criação e inclusão de um indexador específico para o referido fim.

\section{APONTAMENTOS FINAIS}

Como reduzir de maneira eficiente a fome e a pobreza global, certamente é uma questão desafiadora. Essa pergunta é também um desafio quando se trata do emprego dos recursos do Programa Bolsa Família. Qual a melhor maneira de identificar estratégias e mecanismos que ajudem essas famílias a superar a miséria, ou a melhor maneira de combater a fome? Sendo assim, o artigo tomou o desafio de comparar a trajetória e objetivos de programa com alguns dados estatísticos gerais da região para apontar que a discussão da validade dos programas complementares de renda, em especial o PBF, não pode se dar de forma desconectada a criação de um parâmetro, um índice que capture as oscilações inflacionárias pertinentes às famílias de baixa renda da Regional de Santa Maria.

\footnotetext{
${ }^{25}$ Definir a Pesquisa de Orçamento Familiar é uma fase importante do projeto de cálculo de um custo de vida, pois é por meio dela que se investigam os hábitos de consumo das famílias, segundo a distribuição de rendimento.

${ }^{26}$ O ICVSM foi baseado nos pesos definidos pela POF realizada em 2004 e 2005 na cidade de Santa Maria. A amostra contou com 320 famílias e atualmente o índice conta com 370 itens e 874 preços pesquisados. Assim, o objetivo do ICVSM é obter uma medida aproximada do custo de vida na cidade de Santa Maria, e o instrumento técnico utilizado para este fim é o cálculo de números-índices (ICVSM, $n^{\circ} 1,2006$ ).

${ }^{27}$ Neste sentido, entende-se por custo de vida o total das despesas efetuadas para se manter certo padrão de vida. Já um Índice de Custo de Vida mede a variação percentual que os rendimentos de uma pessoa devem sofrer, de forma a permitir que se mantenha o mesmo padrão (IBGE, 2012b).
} 
Essa é uma iniciativa que pode contribuir para que a política pública seja mais independente dos governos e se consolide como um programa de Estado, cujos reajustes estejam ligados a índices e não à vontade de quem ocupa a mais alta posição do executivo federal. Isso implica inverter o foco nas condições econômicas do Estado para as necessidades prementes de sobrevivência das populações que passam pelas experiências diversas da fome. Bem como implica transformar um programa de transferência de renda de iniciativa de governo para incorporá-lo na agenda como política pública de Estado, com renovação de objetivos para um impacto a longo prazo.

Evidentemente, não existe uma cesta definida ou voltada para avaliar se a sequência de reajustes dos benefícios do PBF foram suficientes para manter estável o poder de compra da população de baixa renda da Região Central do Rio Grande Sul ou qualquer outra região brasileira. Com base no banco de dados do ICVSM, embora fosse possível cobrir o período de 2006 até o presente, não seria verossímil para verificar se a diferença entre o poder de compra das famílias de Santa Maria, quando comparadas ao seus semelhantes, tem garatido seu direito a manutenção da renda. Também não poderia se utilizar indicadores de outras regiões do estado, uma vez que não retratam a realidade local.

Sendo assim, a cesta básica continua sendo um importante indicador que mede a perda de poder aquisitivo da população que mais precisa. Na ponta do lápis, havendo uma diferença, e por menor que seja esse desvio, a melhor aderência com a realidade regional conseguirá ampliar as condições de dignidade. Portanto, esse artigo ainda abre novas agendas de pesquisa para um futuro próximo, especialmente, no que tange à criação e estimação dos hábitos das famílias enquadradas pelo PBF na cidade de Santa Maria e região.

\section{REFERÊNCIAS}

ARGENTINA. Decreto $\mathbf{n}^{\mathbf{0}} \mathbf{1 6 . 0 2}$, de 29 de outubro de 2019. Asignaciones Familiares - Régimen General y Disposiciones Especiales. 2009. Disponível em: https://bit.ly/3jUcabZ

BRASIL. Medida Provisória n. 898, de 15 de outubro de 2019. Dispões sobre o abono natalino. Disponível em: https://bit.ly/3hQS7ct. Acesso em: 25 de outubro 2019a.

. Meu Bolsa Família. Disponível em: https://bit.ly/2P6FA8u. Acesso em: 05 de outubro 2019b. . Ministério do Desenvolvimento Social e Combate à Fome (MDS). Desenvolvimento Social e Combate à Fome no Brasil: balanço e desafios. - Brasília, DF: MDS; Secretaria de Avaliação e Gestão da Informação, 2010. 216 p. 
Secretaria de Direitos Humanos da Presidência da República. Direito à alimentação adequada. Brasília: Coordenação Geral de Educação em SDH/PR, 2013. 80 p.

Decreto 9.396, de 30 de maio de 2018. Reajusta valores referenciais de caracterização das situações de pobreza e de extrema pobreza e os de benefícios do Programa Bolsa Família. Disponível em: https://bit.ly/2CVJpuZ. Acesso em: 05 de outubro 2019.

Lei 10.836, de 09 de janeiro de 2004. Dispões sobre a criação do Programa Bolsa Família. Disponível em: https://bit.ly/3hRdSZF. Acesso em: 02 de outubro 2019.

Lei no 10.689, de 13 de junho de 2003. Cria o Programa Nacional de Acesso à Alimentação PNAA. Disponível em: https://bit.ly/2P6GrWK. Acesso em: 06 de outubro 2019.

Decreto no 4.102, de 24 de janeiro de 2002. Regulamenta a Medida Provisória no 18, de 28 de dezembro de 2001, relativamente ao “Auxílio-Gás”. Disponível em: https://bit.ly/2Do4ePy. Acesso em: 06 de outubro 2019.

Decreto $\mathbf{N}^{\circ}$ 3.877, de 24 de julho de 2001. Institui o Cadastramento Único para Programas Sociais do Governo Federal. Disponível em: https://bit.ly/3hRdZV5. Acesso em: 06 de outubro 2019.

Medida Provisória no 2.206-1, de 6 de setembro de 2001. Cria o Programa Nacional de Renda Mínima vinculado à saúde: "Bolsa-Alimentação”. Disponível em: https://bit.ly/3f8xqqQ. Acesso em: 04 de outubro 2019.

Lei No 10.219, de 11 de abril de 2001. Cria o Programa Nacional de Renda Mínima vinculada à educação - "Bolsa Escola”. Disponível em: https://bit.ly/30b7g2i. Acesso em: 05 de outubro 2019.

Constituição (1988). Constituição da República Federativa do Brasil: promulgada em 5 de outubro de 1988. Organização do texto: Yussef Said Cahali. 10. ed. São Paulo: RT, 2008.

BANCO MUNDIAL (WORLD BANK). The State of Social Safety Nets 2018. Washington, DC: The World Bank, 2018 . Word Bank Group. Salvaguardas Contra a Reversão dos Ganhos Sociais Durante a Crise Economica no Brasil. Disponivel em: https://bit.ly/3hSc2rI. Acesso em 24 de out. de 2019. 
BANERJEE, A.; DUFLO, E.; GOLDBERG, N.; KARLAN, D.; OSEI, R.; PARIENTÉ, W.; SHAPIRO, J.; THUYSBAERT, B.; UDRY, C. A Multi-faceted Program Causes Lasting Progress for the Very Poor: Evidence from Six Countries.” Science 348(6236): 1260799. 2015.

.; DUFLO, E. The Economic Lives of the Poor. Journal of Economic Perspectives, v. 21, n. 1, 2007. p. 41-167.

CANABARRO, Aline T.; LOPES, Taize de Andrade M.; FROZZA, Mateus S.; POERSCHKE, Rafael P. Custo de vida em Santa Maria/RS: histórico e evolução da inflação no município (2006-2013).

Disciplinarum Scientia - Ciências Sociais Aplicadas, Santa Maria-RS, v. 9, n. 1, 2013. p. 31-42. Disponível em: https://bit.ly/3396LHU

CEPAL. Base de datos de programas de protección social no contributiva en América Latina y el Caribe. 2019. Disponível em: https://bit.ly/3hSc9DE

CRESPO, Antônio Pedro A.; GUROVITZ, Elaine. A pobreza como um fenômeno multidimensional. Revista ERA Eletrônica, São Paulo, v. 1, n. 2, p. 1-12, jul. /dez. 2002.

DUFLO, E. The Economist as Plumber. MIT Department of Economics Working Paper n. 17-03, jan. 2007. Disponível: http://dx.doi.org/10.2139/ssrn.2927153

. Field Experiments in Development Economics. Advances in Economics and Econometrics: Theory and Applications, Ninth World Congress, v. 2, BLUNDELL, R.; WHITNEY, N.; PERSSON, T. (eds.). New York, NY: Cambridge University Pres. 2006a. 322-348.

. Poor but Rational? In BANERJEE, A., DILIP, M.; BENABOU, R. (eds.) Understanding Poverty. New York, NY: Oxford University Press. 2006b.

GRAZIANO DA SILVA, J. A nova Dinâmica da agricultura brasileira. Campinas, SP: UNICAMP. IE, 1996. 208 p.

HAGEMAN, R. P. The Variability of Inflation Rates across Household Types. Journal of Money, Credit, and Banking, vol. 14, Part 1, November, 1982, pp. 494-510.

HOFFMANN, R. Determinantes da insegurança alimentar no Brasil em 2004 e 2009. Segurança Alimentar e Nutricional. 2013. 
IBGE. Censo Demográfico - 2010: Características da população e dos domicílios. Resultados do universo. Rio de Janeiro: IBGE, 2011. Disponível em: https://bit.ly/2CU7Bhf. Acesso em: ago. 2013.

. Síntese de indicadores sociais: uma análise das condições de vida da população brasileira: 2018 / IBGE, Coordenação de População e Indicadores Sociais. - Rio de Janeiro : IBGE, 2018. 151 p.

ÍNDICE DO CUSTO DE VIDA DE SANTA MARIA (ICVSM). Vários anos. Santa Maria: UNIFRA. Disponível em: http://www.unifra.br/ICVSM/. Acesso em 05out. 2019.

MATTOS B. M. Uma abordagem Seniana do Programa Bolsa Família. Dissertação (Mestrado em Economia). Universidade Federal do Rio Grande do Sul. Porto Alegre, 2011.

MDS, Ministério do Desenvolvimento Social. Câmara Interministerial de Segurança Alimentar e Nutricional (CAISAN). Disponível em: https://bit.ly/3hPrc0K. Acesso em 25 de maio de 2019.

MDSA, Ministério do Desenvolvimento Social e Agrário. Relatórios de Informações Sociais. Disponível em: https://bit.ly/3jXuPDC. Acesso em: 01 set. 2018.

MEXICO. Decreto $n^{0}$ de 05 de setembro de 2014. Decreta que se crea la Coordinación Nacional de PROSPERA Programa de Inclusión Social. 2014. Disponível em: https://bit.ly/3glgwH2

MICHAEL, R. T. Variation across Households in the Rate of Inflation. Journal of Money, Credit, and Banking, vol. 11, n. 1, 1979.

MIURA, Irene Kazumi. Políticas públicas: conceitos básicos. USP/SP, 2015. Disponível em: https:// bit.ly/2EAmlCm. Acesso em 12 out. 2019.

NASCIMENTO, A. F.; REIS, C. N. Os programas de transferência condicionada de renda na américa latina: especificidades de uma realidade que se mantém. Revista de Políticas Públicas, São Luis, v. 13, n.2, p. 183-193, jul./dez., 2009.

OLIVEIRA, S. V. et al. Análise do índice fuzzy de pobreza multidimensional em populações urbanas: um estudo de caso em Santa Maria (RS). Estudos do CEPE, Santa Cruz do Sul, p. 81-99, set. 2018. ISSN 1982-6729. Disponível em: https://bit.ly/2PbYDOE.. Acesso em: 10 out. 2018. 
PAIVA, L. H.; PEREIRA, E. S.; COTTA. Uma agenda para o Programa Bolsa Família. In: Bolsa Família 15 Anos (2003-2018). SILVA, Tiago Falcão (Org.). Brasília: Enap, 2018. 530 p.

SAGI Secretaria de Avaliação e Gestão da Informação (SAGI). Relatórios de Informações Sociais. Cadastro Único Bolsa Família, 11 de outubro de 2019.

SCHWARTZMAN, S. Vantagens e Desvantagens das Linhas de Pobreza. IETS, 2003.

SEN, A. K. Desenvolvimento como liberdade. Tradução Laura Teixeira Motta. São Paulo: Companhia das Letras, 2000.

Desigualdade reexaminada. Record, 2008.

SNYDER, E. M. Cost of Living Indices for Special Classes of Consumers. Staff Paper 7, Government Price Statistics, 1961. p. 337-372.

SOUZA, C. Estado da Arte da Pesquisa em politicas públicas. In: HOCHMAN, Gilberto; ARRETCHE, M.; MARQUES, E. (Orgs). Políticas Públicas no Brasil. Rio de Janeiro: Fiocruz, 2007.

USDA. Farm Bill. United States Department of Agriculture. 2019.

VIEIRA, C. A. et al. Pobreza multidimensional: um estudo de caso das privações básicas na região nordeste de Santa Maria/RS. Economia e Desenvolvimento, v. 30, n. 3, p. 1-12, set., 2018. Disponível em: https://bit.ly/2ExsS0t. Acesso em: 10 out. 2018.

ZAMBAM, Neuro José; KUJAWA, Henrique Aniceto. As políticas públicas em Amartya Sen: condição de agente e liberdade social. Revista Brasileira de Direito, Passo Fundo, v. 13, n. 1, p. 60-85, mar. 2017. 
